\title{
Effect of shade and thermo-mechanical viscosity stimulation methods on the rheological properties of nanohybrid resin composite
}

\author{
Spadacini, Alessandro ; Barabanti, Nicola ; Baldi, Francesco ; Özcan, Mutlu ; Cerutti, Antonio
}

\begin{abstract}
The aim of the present study is to measure the rheological properties of nanohybrid resin composite of three shades in pre-polymerized phase using different thermomechanical stimulations. Nanohybrid composite (Kerr Herculite XRV Ultra) in enamel, dentin, and incisal shades was included. Rheological measurements were made with a rotational rheometer in dynamic oscillation mode using three methods: (a) Strain Sweep test explored a range of deformation $\gamma 0$ from 0.025 to $3 \%$ with a frequency $\omega=1 \mathrm{~Hz}$ (temperature set at 25 and 65 ${ }^{\circ} \mathrm{C}$ ), (b) Frequency Sweep test explored frequencies between 1 and $100 \mathrm{rad} / \mathrm{s}$ applying a deformation $\gamma 0=0.5 \%$ (temperature set at $25 ; 45 ; 65{ }^{\circ} \mathrm{C}$ ), and (c) Ramp Temperature test explored a heating phase from 25 to $75{ }^{\circ} \mathrm{C}$ then a cooling phase back to $25{ }^{\circ} \mathrm{C}$ applying a $\gamma 0=0.5 \%$ and a $\omega=10 \mathrm{rad} / \mathrm{s}$. Data were analyzed using a three-way ANOVA and Tukey's test $(\alpha=0.05)$. Viscosity measurement $(p<0.05)$ and shade of the composites $(p<0.05)$ significantly affected the results. Viscosity turned out to be subordinate to strain amplitude, frequency, temperature, and axial force applied during each test. Enamel shade was the most viscous whereas dentin shade was $8 \%$ less viscous $(\mathrm{p}<0.05)$. The incisal shade was significantly less viscous $(70 \%)$ than enamel $(\mathrm{p}<0.05)$. Pre-heating decreased viscosity of incisal shade $(30 \%)$ above $50{ }^{\circ} \mathrm{C}$ but this value was 90 and $98 \%$, respectively, for strain and frequency sweep test. Preheating had a side effect as in the cooling phase, viscosity increased from 66 to $450 \%$ exceeding the value recorded at the beginning of the test. Preheating was not effective to reduce viscosity, and may reveal some side effects. The composite tested might not be pre-heated above $45{ }^{\circ} \mathrm{C}$.
\end{abstract}

DOI: https://doi.org/10.1080/01694243.2016.1197089

Posted at the Zurich Open Repository and Archive, University of Zurich

ZORA URL: https://doi.org/10.5167/uzh-146594

Journal Article

Accepted Version

Originally published at:

Spadacini, Alessandro; Barabanti, Nicola; Baldi, Francesco; Özcan, Mutlu; Cerutti, Antonio (2017). Effect of shade and thermo-mechanical viscosity stimulation methods on the rheological properties of nanohybrid resin composite. Journal of Adhesion Science and Technology, 31(1):100-108.

DOI: https://doi.org/10.1080/01694243.2016.1197089 


\title{
Effect of shade and thermo-mechanical viscosity stimulation methods on the rheological properties of nanohybrid resin composite
}

\author{
Alessandro Spadacini, DMDa / Nicola Barabanti, DMD ${ }^{\mathrm{b}} /$ Francesco \\ Baldi, DDS $/$
}

Mutlu Özcan, DDS, Dr.med.dent., PhD ${ }^{d} /$ Antonio Cerutti, MD, DDS ${ }^{\mathrm{e}}$

${ }^{a}$ Clinical Lecturer, University of Brescia, Department of Restorative Dentistry, Brescia, Italy ${ }^{b}$ Research Fellow, University of Brescia, Department of Restorative Dentistry, Brescia, Italy ${ }^{c}$ Research Fellow, University of Brescia, Department of Industrial and Mechanical Engineering, Brescia, Italy

${ }^{d}$ Professor, University of Zurich, Dental Materials Unit, Center for Dental and Oral Medicine,

Clinic for Fixed and Removable Prosthodontics and Dental Materials Science, Zurich, Switzerland

eProfessor, University of Brescia, Department of Restorative Dentistry, Brescia, Italy

Short title: Rheological properties of different shades of composite as a function of temperature

Correspondance to: Nicola Barabanti University of Brescia, Restorative Department, School of Dentistry. P.le Spedali Civili, 1, 25123 Brescia, Italy. nicola.barabanti@gmail.com 
Abstract: To measure the rheological properties of nanohybrid resin composite of 3 shades in pre-polymerized phase using different thermomechanical stimulations. Nanohybrid composite (Kerr Herculite XRV Ultra) in enamel, dentin and incisal shades were included. Rheological measurements were made with a rotational rheometer in dynamic oscillation mode using 3 methods: a) Strain sweep test explored a range of deformation y0 from $0.025 \%$ to $3 \%$ with a frequency $\omega=1 \mathrm{~Hz}$ (temperature set at 25 and $65^{\circ} \mathrm{C}$ ), b) Frequency Sweep test explored frequencies between 1 and $100 \mathrm{rad} / \mathrm{s}$ applying a deformation $\mathrm{y} 0=0,5 \%$ (temperature set at $25 ; 45 ; 65^{\circ} \mathrm{C}$ ) and c) Ramp temperature test explored a heating phase from $25^{\circ} \mathrm{C}$ to $75^{\circ} \mathrm{C}$ then a cooling phase back to $25^{\circ} \mathrm{C}$ applying a $\gamma 0=0,5 \%$ and a $\omega=$ 10rad/s. Data were analyzed using 3-way ANOVA and Tukey`s test (alpha=0.05). Viscosity measurement $(p<0.05)$ and shade of the composites $(p<0.05)$ significantly affected the results. Viscosity turned out to be subordinate to strain amplitude, frequency, temperature and axial force applied during each test. Enamel shade was the most viscous whereas dentin shade was $8 \%$ less viscous $(p<0.05)$. The incisal shade was significantly less viscous $(70 \%)$ than enamel $(p<0.05)$. Pre-heating decreased viscosity of incisal shade $(30 \%)$ above $50^{\circ} \mathrm{C}$ but this value was $90 \%$ and $98 \%$ respectively for strain and frequency sweep test. Preheating had a side effect as in the cooling phase, viscosity increased from 66 to $450 \%$ exceeding the value recorded at the beginning of the test. Preheating was not effective to reduce viscosity, and may reveal some side effects. The composite tested might not be pre-heated above $45^{\circ} \mathrm{C}$

Keywords: adhesive dentistry, dental composite, pre-heating, rheology 


\section{Introduction}

Resin composites (hereon: composites) are the most commonly used restorative material in reconstructive dentistry, as they replaced the traditional restorative material, amalgam, surpassing it for both aesthethic and functional properties. The consistency is one of the most important features in a composite since it highly affects its manipulation [1].

Currently available composites show great difference in consistency dictated by the size and shape of the inorganic filler and properties of the resin matrix [2-7]. Composites are viscoelastic materials having both viscous properties such as oils and elastic properties such as ceramics [8-10]. Viscosity is an intrinsic feature that describes the resistance opposed by the material to an imposed flow motion. This feature influences the handling properties of the composite, quality of the final restoration and the time needed to build up $[1,3,8,11-13]$.

Researchers studied some methods to reduce the viscosity of composites in order to make them easier to use in restorative dentistry or make them suitable for adhesive cementation procedures. Pre-heating the composite is by far the most adopted method to achieve this target. This procedure may also improve degree of conversion, marginal adaptation and at the same time reduces microleakage [14-16].

Various methods have been employed to measure the dynamic viscoelastic properties of composites such as rotational rheometer, press method or dynamic oscillatory rheometer and more recently the use of vertical oscillation rheometer was proposed.

The objectives of this study therefore were to measure the rheological properties of three shades of nanohybrid composite in pre-polymerized phase at different thermo-mechanical stimulations using a rotational rheometer in dynamic oscillation mode. The null hypotheses tested were that a) there would be no difference in the viscosity among different shades of the same composite and b) different thermo-mechanical stimulation methods would not affect the rheology of the composite tested. 


\section{Materials and Methods}

The brands, chemical compositions, manufacturers of the materials used in this study are listed in Table 1.

Specimen preparation

Enamel, dentin and incisal shades of nanohybrid composite (Kerr Herculite XRV Ultra, Bioggio, Swizerland) were selected for the study. The specimens were obtained extruding 28 $\mathrm{mm}$ length of composite from the tube, manipulated with a stainless steel spatula and placed between the plates of the rheometer (Fig. 1). A rotational rheometer was used for the study (Ares G2, TA Instruments, New Castle, UK) applying shear stresses in dynamic oscillation mode with a parallel plate configuration (25 mm diameter) (Fig. 2). Each specimen was prepared immediately before the execution of the test and was intended for single use only. After composite was placed on the lower plate of the rheometer, the upper plate was moved downward to adjust the gap to a thickness of $1.3 \mathrm{~mm}$. Excess composite present around the circumference of the plate was removed prior to the measurements.

Viscosity measurement methods

Strain Sweep: This test has been performed at two different temperatures $\left(25\right.$ and $\left.65^{\circ} \mathrm{C}\right)$. The rheometer was set at specific temperature exploring deformation yo from $0.025 \%$ to $3 \%$ with a frequency of $\omega=1 \mathrm{~Hz}$. The distance between the two plates was kept standard at $1.3 \mathrm{~mm}$.

Frequency Sweep: This test has been performed at three different temperatures (25-45$65^{\circ} \mathrm{C}$ ). The rheometer was set at specific temperature with a deformation of $\mathrm{y}_{0}=0.5 \%$, exploring frequencies between 1 and $100 \mathrm{rad} / \mathrm{s}$. The distance between the two plates was kept standard at $1.3 \mathrm{~mm}$.

Ramp Temperature: In this method, the rheometer was set at frequency $\omega=10 \mathrm{rad} / \mathrm{s}$, deformation $y_{0}=0.5 \%$, by heating the specimen from 25 to $75^{\circ} \mathrm{C}\left(5^{\circ} \mathrm{C} / \mathrm{min}\right)$ and then cooing 
down to $25^{\circ} \mathrm{C}$. The test has been executed at an axial force of 1 to $4 \mathrm{~N}$, increased from 5 to 8 $\mathrm{N}$ and maintained at this magnitude of force during the experiments.

The difference between shear stress and shear strain allowed the calculation of the complex viscosity of the specimen:

$$
\eta^{*}=1 / \omega \cdot \tau_{0} / \gamma_{0}
$$

Where $\eta^{*}$ is the complex viscosity, $\omega$ is the frequency, t0 is the shear stress and $\mathrm{y} 0$ is the shear strain.

All these tests have been performed in a light filtered room in order not to avoid the early polymerization of the specimens. All measurements were repeated for 3 times.

Statistical analysis

All statistical procedures were performed using the Statistical Package for Medical Science (SPSS 21.00 for Windows software, SPSS Inc., Chicago, IL, USA). Mean viscosity values were analyzed using 3-way ANOVA and Tukey`s test test based on the 3 shades and 3 viscosity measurement method parameters (alpha=0.05). P values less than 0.05 were considered to be statistically significant in all tests.

\section{Results}

Viscosity measurement $(p<0.05)$ and shade of the composites $(p<0.05)$ significantly affected the results. Interactions terms were also significant $(p<0.05)$.

Enamel and dentin shades showed comparable values in viscosity $(p>0.05)$. The incisal shade was significantly less viscous (nearly $70 \%)$ than enamel $(p<0.05)$.

Strain sweep test showed a reduction in viscosity while increasing the deformation. A very similar behavior was observed for enamel and dentin shades (lower viscosity for $65^{\circ} \mathrm{C}$ than $25^{\circ} \mathrm{C}$ ), while incisal shade showed a tendency to become more viscous at 65 than $25^{\circ} \mathrm{C}$ for deformations $\mathrm{y} 0>0.3 \%$ (Fig. 3). 
With Frequency Sweep test all the shades showed a reduction in viscosity while increasing the frequency. Temperature affected the results as well; the higher the temperature was, the lower the viscosity. This effect was not observed for the incisal shade, that showed higher viscosity at $65^{\circ} \mathrm{C}$ than at $45^{\circ} \mathrm{C}$ (Fig. 4).

Ramp Temperature test showed a progressive reduction of the complex viscosity of all shades heating from 25 to $45^{\circ} \mathrm{C}$ (from 29 to $48 \%$ ) but this trend was maintained up to $75^{\circ} \mathrm{C}$ for enamel and dentin shades. With this method, incisal shade revealed an opposite trend and started increasing its viscosity above $50^{\circ} \mathrm{C}$ (Fig 5). This test showed also that the stronger the axial force was, the higher the viscosity results (Fig. 6). Ramp Temperature test also revealed that during the cooling phase, all three shades showed a dramatic and progressive increase in their viscosity. This trend continued far above the values detected at the beginning of the tests from 66 to $450 \%$.

\section{Discussion}

This study was undertaken in order to measure the rheological properties of three shades of nano-hybrid composite in pre-polymerized phase at different thermo-mechanical stimulations using a rotational rheometer in dynamic oscillation mode. Based on the results of this study, the null hypothesis tested that there would be no difference in the viscosity among different shades of the same composite tested could rejected. Likewise, since thermo-mechanical stimulation methods affected the results, the second hypothesis could also be rejected.

The three different shades of the tested nano-composite in this study, demonstrated different viscosity levels being particularly different for the incisal shade. Temperatures above $50^{\circ} \mathrm{C}$ presented unexpected behavior in the rheological properties of this shade. In general, viscosity secondarily affected by the strain amplitude, frequency, temperature and the axial force applied during each test. Accordingly, ramp temperature test showed that $95 \%$ (average) of total reduction of viscosity ( $30 \%$ average) could be reached already at $45^{\circ} \mathrm{C}$. 
Surprisingly, the viscosity increases considerably during the cooling phase omitting the advantage obtained from pre-heating.

From clinical perspective, there is remarkable limitation of pre-heating the composite since after this procedure it is impossible to avoid the cooling of composite from extraction out of the tube until application in the cavity intraorally. Nevertheless, Strain Sweep and Frequency Sweep tests showed an average reduction of viscosity of more than 90 to $98 \%$, respectively for the composite tested.

Numerous studies focused on the mechanical properties of photo-polymerized composites but limited number of studies has dealt with the rheological properties of unpolymerized composites. In fact, filler shape and size, resin matrix composition and interactions between them affect handling properties of composites including viscosity that may consequently affect their polymerization [2-7].

Especially during layering, when several shades of composites are used, shade, translucency, or opacity of the resin composite after polymerization show significant effect on the final result [18]. For this reason, to simplify the procedure, only shade A2 of the same brand of nano-hybrid composite was used. Filler shape strongly affects the color of composite resins, and other filler properties such as filler particle size and filler content exert significant influences on the refractive index of resin composites $[19,20]$. According to the manufacturer of the nano-hybrid composite used in this study, all enamel, dentin and incisal shades were composed of 20-50 nm size silica nanofillers and 0.6 $\mu \mathrm{m}$ Barium fillers. While resin matrices such as bisphenol-A-glycidyl methacrylate (bis-GMA), urethane dimethacrylate (UDMA), 10 methacryloyloxydecyl dihydrogen phosphate (MDP), triethyleneglycol dimethacrylate (TEGDMA), 2-hydroxyethyl methacrylate (HEMA) contribute little, it is typically the inorganic filler component (barium, yttrium, ytterbium, zinc, aluminium, strontium, and zirconium) that contributes most to the refractive index and radiopacity of the resin-based materials [21]. 
Since both the matrix and the barium filler amount were similar in the tested material, the variation in the results between incisal and dentin shades in viscosity results seem to be influenced highly by the amount of titanium dioxide $\left(\mathrm{TiO}_{2}\right)$ and the pigments in the tested material. Unfortunately, exact amounts were not provided in material safety sheets. Typically, $\underline{\text { dry }} \mathrm{TiO}_{2}$ is added to the composite matrix or $\mathrm{TiO}_{2}$ is milled into a "resin" to make a liquid $\mathrm{TiO}_{2}$ dispersion to be added in order to achieve a consistent shade of the resin composite [22]. The two methods of pigment addition can yield to differences in processing time, consistency, matrix viscosity, flow and leveling, and polymerization time. Matrix viscosity and thixotropy also influence flow, uniformity, size distribution, moisture, and gel time of the resin matrix. In addition, the type and particle size of the $\mathrm{TiO}_{2}$ and the chemistry of the resin the pigment that is dispersed in, can impact viscosity. Thus, further investigations are needed on the type of $\mathrm{TiO}_{2}$ addition method to obtain the $\mathrm{A} 2$ shade for dentin and incisal composites in order to verify its effect on the rheological properties of resin composites.

Future studies should also focus on importance of degree of polymerization and shrinkagestress behaviour after different pre-heating conditions also considering the shade effect.

\section{Conclusions}

From this study, the following could be concluded:

1. Viscosity of resin composites after pre-heating varied depending on the shade of the resin composite.

2. Viscosity testing methods showed different viscosity levels of the composites tested.

3. Increasing the temperature during pre-heating up to $70^{\circ} \mathrm{C}$ decreases the viscosity of enamel and dentin shades of the nano-composite tested but the incisal shade above $45^{\circ} \mathrm{C}$ show increase in viscosity.

4. Preheating and subsequent cooling of the composite increased the viscosity for all the shades of composite. 


\section{Clinical Relevance}

Pre-heating nano-composite resin up to $45^{\circ} \mathrm{C}$ is sufficient to decrease viscosity of enamel and dentin shade of the nano-composite tested but the incisal shade did not benefit from preheating.

\section{Acknowledgement}

The authors acknowledge the entire staff members of the Materials Science and Technology Laboratory, Department of Mechanical and Industrial Engineering, University of Brescia, for assistance during the experimental procedures.

\section{Conflict of interest}

The authors did not have any commercial interest in any of the materials used in this study. 


\section{References}

[1] Opdam NJM, Roeters JJM, Peters TCRB, Burgersdijk RCW, Kuijs RH. Consistency of resin composites for posterior use. Dent Mater 1996;12:350-354.

[2] Leinfelder KF, Prasad A. A new condensable composite for the restoration of posterior teeth. Dent Today 1998;17:112-116.

[3] Lee JH, Um CM, Lee IB. Rheological properties of resin composites according to variations in monomer and filler composition. Dent Mater 2006;22:515-526.

[4] Lee IB, Cho BH, Son HH, Um CM. Rheological characterization of composites using a vertical oscillation rheometer. Dent Mater 2007;23:425-432.

[5] Lee I, Chang J, Ferracane J. Slumping resistance and viscoelasticity prior to setting of dental composites. Dent Mater 2008;24:1586-1593.

[6] Beun S, Bailly C, Devaux J, Leloup G. Physical, mechanical and rheological characterization of resin-based pit and fissure sealants compared to flowable resin composites. Dent Mater 2012;28:349-359.

[7] Al-Ahdal K, Silikas N, Watts D. Rheological properties of resin composites according to variations in composition and temperature. Dent Mater 2014:30:517-524.

[8] Jacobsen PH, Whiting R, Richardson P. Viscosity of setting anterior restorative materials. Br Dent J 1977;12:393-396.

[9] Duran RL, Powers JM, Craig RG. Viscoelastic and dynamic properties of soft liners and tissue conditioners. J Dent Res1979;58:1801-1807.

[10] De Kee D, Chan Man Fong CF. Rheological properties of structured fluids. Polym Eng Sci 1994;34:438-445.

[11] Ferracane JL, Moser JB, Greener EH. Rheology of composite restoratives. J Dent Res 1981;60:1678-1685.

[12] Bayne SC, Thompson JY, Swift EJ, Stamatiades P, WilkersonM. A characterization of first-generation flowable composites. J Am Dent Assoc 1998;129:567-577. 
[13] Lee IB, Son $\mathrm{HH}$, Um CM. Rheological properties of flowable,conventional hybrid, and condensable composite resins. Dent Mater 2003;19:298-307.

[14] Acquaviva PA, Gagliani M, Mangani F, Adami G, Cerutti F, Cerutti A. Pre-heating influence on the conversion degree of composite luting materials, J Dent 2009;37:610-615.

[15] Vieno S, Madini L, Barabanti N, Alessandri I, Gagliani M, Cerutti A. Indirect resin composite restorations: evaluation of polymerization of luting agents by means of microRaman spectrophotometry. Minerva Stomatol 2009;58:1-8.

[16] Fróes-Salgado NR, Silva LM, Kawano Y, Francci C, Reis A, Loguercio AD, Composite pre-heating: effects on marginal adaptation, degree of conversion and mechanical properties. Dent Mater 2010;26:908-914.

[17] Wagner WC1, Aksu MN, Neme AM, Linger JB, Pink FE, Walker S, Effect of pre-heating resin composite on restoration microleakage. Oper Dent 2008 ;33:72-78.

[18] Kim HS, Um CM. Color differences between resin composites and shade guides. Quintessence Int 1996;27:559-567.

[19] Lee YK, Lim BS, Kim CW. Effect of surface conditions on the color of dental resin composites. J Biomed Mater Res 2002;63:657-663.

[20] Arikawa H, Kanie T, Fujii K, Takahashi H, Ban S. Effect of filler properties in composite resins on light transmittance characteristics and color. Dent Mater J 2007;26:38-44.

[21] Pekkan G, Özcan M. Radiopacity of different resin-based and conventional luting cements compared to human and bovine teeth. Dent Mater J 2012;31:68-75.

[22] Jeries B, Keeler R. Pigment influences on the properties of highly filled resin systems. AOC, LLC Technical report. October 1-3, 2003, aoc.resins.com. 


\section{Captions to figures:}

\section{Tables:}

Table 1. The brands, chemical compositions, manufacturers of the materials used in this study.

\section{Figures:}

Fig. 1 Nanohybrid composite extruded from the tube at standard length.

Fig. 2 The rotational rheometer used in this study applying shear stresses in dynamic oscillation mode.

Fig. 3 The viscosity of incisal shade of the nanocomposite using Strain Sweep test.

Fig. 4 The mean viscosity of enamel, dentin and incisal shades of the nanocomposite using Strain Sweep test at 25,45 and $65^{\circ} \mathrm{C}$.

Fig. 5 The mean viscosity of enamel, dentin and incisal shades of the nanocomposite using Ramp Temperature test

Fig. 6 Effects of the axial force in Ramp Temperature test for enamel, dentin and incisal shades of the nanocomposite. 
Tables:

\begin{tabular}{|c|c|c|c|}
\hline Brand & Chemical Composition & Manufacturer & Batch Number \\
\hline XRV Enamel (A2) & $\begin{array}{l}\text { bis-GMA, TEGDMA, } \\
\text { prepolymerized fillers, silica } \\
\text { nanofiller ( } 20-50 \mathrm{~nm} \text { nanoparticles), } \\
\text { Barium submicron fillers }(0.6 \mu \mathrm{m} \\
\text { average size), titanium dioxide } \\
\left(\mathrm{TiO}_{2}\right) \text { and pigments }\end{array}$ & Kerr, Bioggio, Switzerland & 3302434 \\
\hline XRV Dentin (A2) & $\begin{array}{l}\text { bis-GMA, TEGDMA, } \\
\text { prepolymerized fillers, silica } \\
\text { nanofiller ( } 20-50 \mathrm{~nm} \text { nanoparticles), } \\
\text { Barium submicron fillers }(0.6 \mu \mathrm{m} \\
\text { average size), titanium dioxide } \\
\left(\mathrm{TiO}_{2}\right) \text { and pigments }\end{array}$ & Kerr & 3302475 \\
\hline XRV Incisal (A2) & $\begin{array}{l}\text { bis-GMA, TEGDMA, } \\
\text { prepolymerized fillers, silica } \\
\text { nanofiller ( } 20-50 \mathrm{~nm} \text { nanoparticles), } \\
\text { Barium submicron fillers }(0.6 \mu \mathrm{m} \\
\text { average size), titanium dioxide } \\
\left(\mathrm{TiO}_{2}\right) \text { and pigments }\end{array}$ & Kerr & 3302413 \\
\hline
\end{tabular}

Table 1. The brands, chemical compositions, manufacturers of the materials used in this study. 


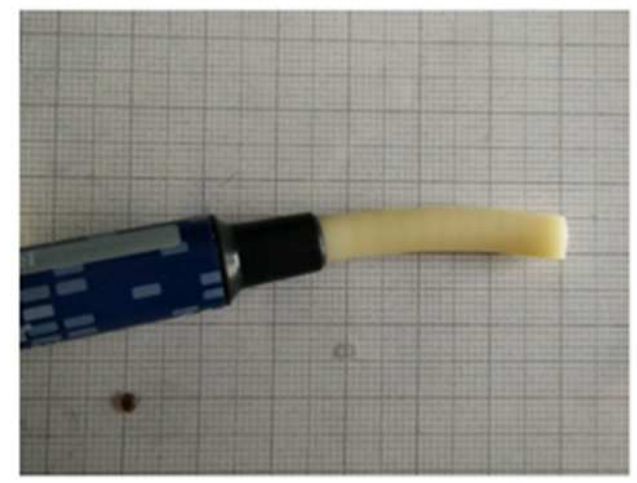

Figure 1

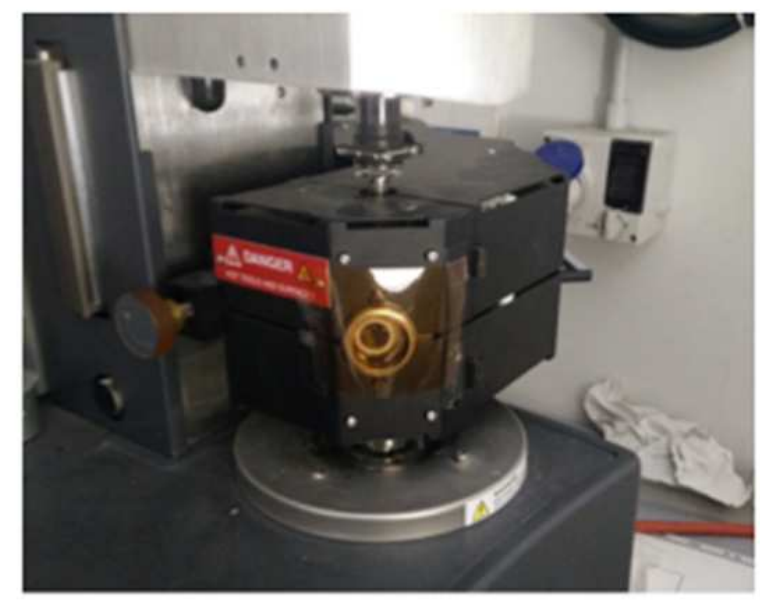

Figure 2

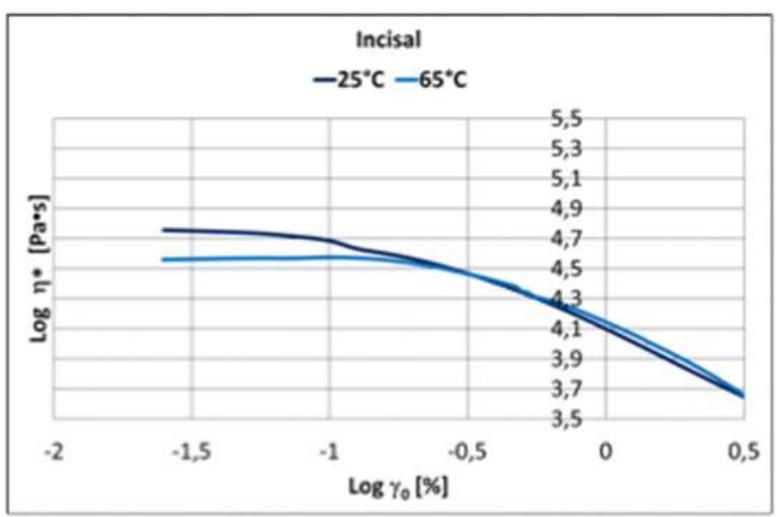

Figure 3 


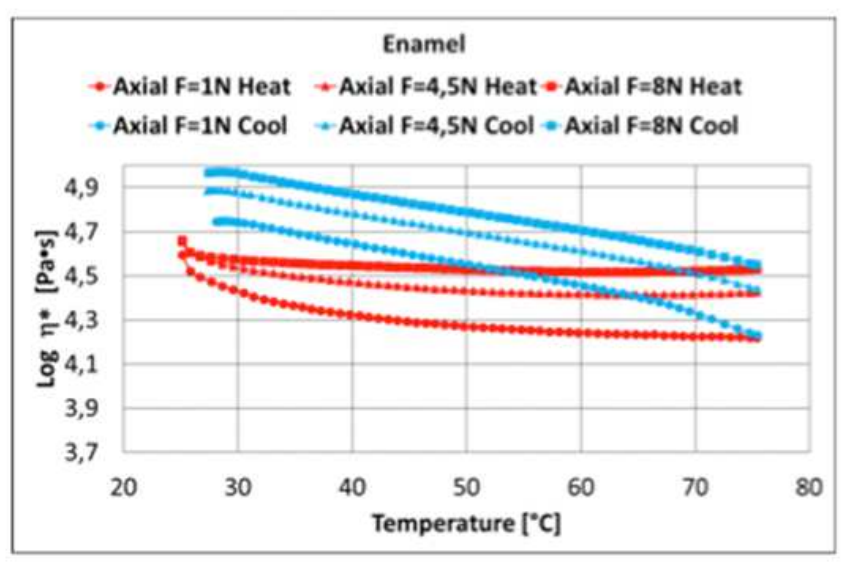

Figure 4

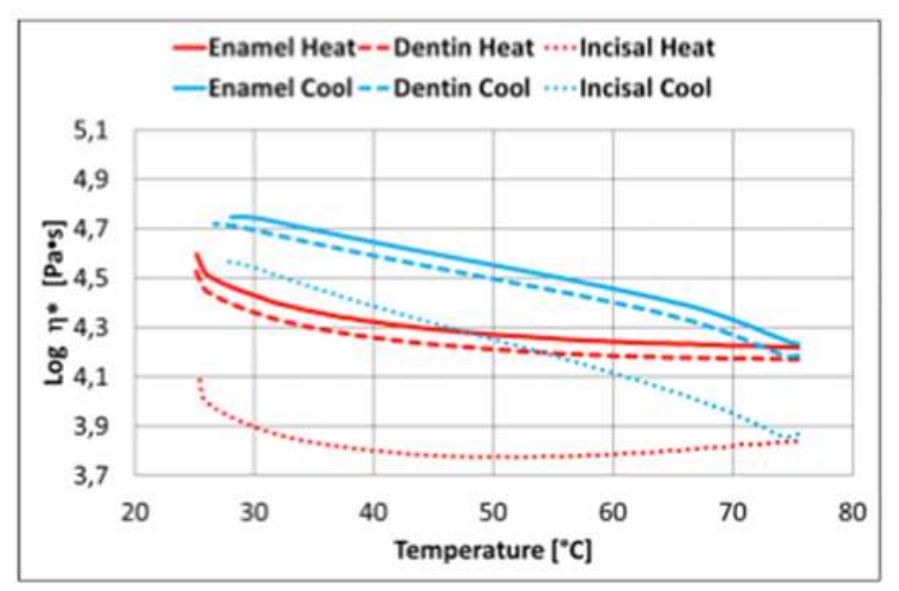

Figure 5

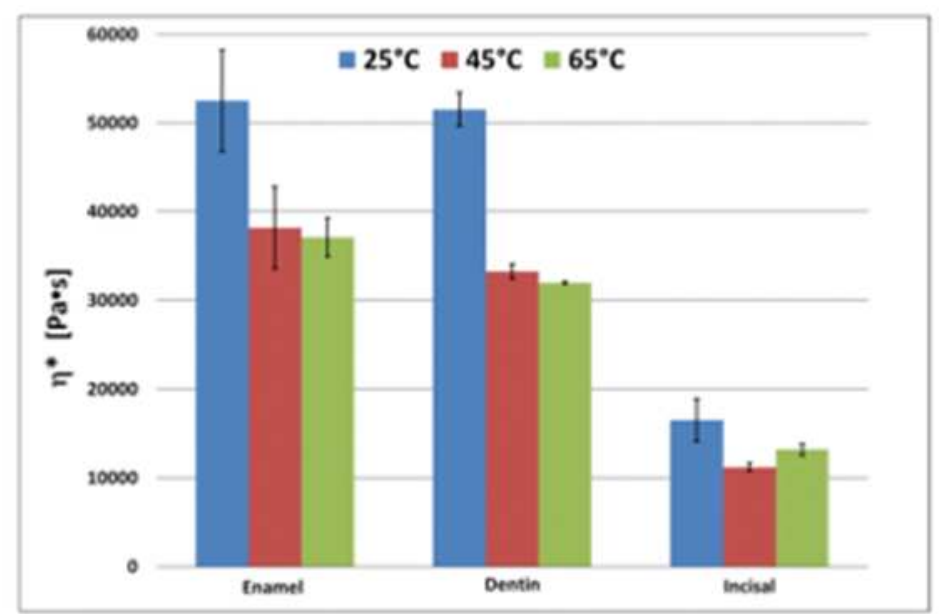

Figure 6 